\title{
Sucralose promotes accumulation of reactive oxygen species (ROS) and adipogenesis in mesenchymal stromal cells
}

\author{
Nabanita Kundu', Cleyton C. Domingues' ${ }^{1}$, Jay Patel ${ }^{1}$, Mohammed Aljishi', Neeki Ahmadi', Mona Fakhri', \\ Allison C. Sylvetsky ${ }^{2}$ and Sabyasachi Sen ${ }^{1 *}$ (D)
}

\begin{abstract}
Consumption of non-nutritive sweeteners (NNS) has been consistently associated with obesity and cardiometabolic disease in epidemiologic studies. Herein, we investigated effects of sucralose, a widely used NNS, at a cellular level. We wanted to investigate effect of sucralose on reactive oxygen species accumulation and adipogenesis in a human adipocyte tissue-derived mesenchymal stromal cells (MSCs) in a controlled fashion.

Methods: In vitro experiments were conducted on commercially available MSCs obtained from human adipose tissue. hMSCs were exposed with sucralose at $0.2 \mathrm{mM}$ (a concentration which could plausibly be observed in the circulatory system of high NNS consumers) up to $1.0 \mathrm{mM}$ (supra-physiologic concentration) in the presence of both normal and high glucose media to detect a dose response based on the outcome measures. Reactive oxygen species (ROS) were detected using Mitosox Red staining and further analyzed by ImageJ and gene expression analysis. Effect of sucralose on adipogenic differentiation was observed in different concentrations of sucralose followed by gene expression analysis and Oil Red $O$ staining.
\end{abstract}

Results: Increased ROS accumulation was observed within $72 \mathrm{~h}$ of exposure. Increased adipogenesis was also noted when exposed to higher dose of sucralose.

Conclusion: Sucralose promotes ROS accumulation and adipogenesis in human adipose tissue derived mesenchymal stromal cells.

Keywords: Non-nutritive sweeteners, Mesenchymal stromal cells, Adipogenesis, Obesity, Diabetes, Reactive oxygen species

\section{Introduction}

Consumption of added sugars is associated with the development of obesity, diabetes, high blood pressure, cardiovascular disease (CVD), and dyslipidemia [1-4]. The American Heart Association (AHA) recommends that calories from added sugar should not exceed 100 or $150 \mathrm{kcals}$ per day for adult females and males, respectively [5]. Non-nutritive sweeteners (NNS) are commonly used as a replacement for added sugar, as they are sweet but contain no or few calories. The US Food and Drug

\footnotetext{
* Correspondence: ssen1@gwu.edu

'The George Washington University, 2300 Eye ST. NW, Washington DC 20037, USA

Full list of author information is available at the end of the article
}

Administration (FDA) regulates six NNS (saccharin, acesulfame-potassium, sucralose, aspartame, neotame, and advantame) and sets acceptable daily intake limits for each individual sweetener [6].

The National Health and Nutrition Examination Survey (NHANES) 2009-2012 [7] reported 25\% of children and more than $41 \%$ of adults consume NNS directly or indirectly in foods and beverages in the USA. Whether as NNS have beneficial effects on cardiometabolic health or rather promote weight gain and metabolic dysfunction in humans remains controversial. Numerous epidemiologic studies have shown associations between NNS consumption with obesity, diabetes, and stroke [8-11]. Potential mechanisms for these observations have been

\section{BMC}

(c) The Author(s). 2020 Open Access This article is licensed under a Creative Commons Attribution 4.0 International License, which permits use, sharing, adaptation, distribution and reproduction in any medium or format, as long as you give appropriate credit to the original author(s) and the source, provide a link to the Creative Commons licence, and indicate if changes were made. The images or other third party material in this article are included in the article's Creative Commons licence, unless indicated otherwise in a credit line to the material. If material is not included in the article's Creative Commons licence and your intended use is not permitted by statutory regulation or exceeds the permitted use, you will need to obtain permission directly from the copyright holder. To view a copy of this licence, visit http://creativecommons.org/licenses/by/4.0/ The Creative Commons Public Domain Dedication waiver (http://creativecommons.org/publicdomain/zero/1.0/) applies to the data made available in this article, unless otherwise stated in a credit line to the data. 
identified in in vitro and in vivo studies. For example, in human functional magnetic resonance imaging studies, less reward (activation of the dopaminergic system) was observed when subjects ingested NNS compared to glucose [12]. In mice, saccharin exposure led to changes in the gut microbiome causing glucose intolerance [13]. Similarly, aspartame also caused microbiome changes and altered short-chain fatty acid production [14]. In mature mouse adipocytes, NNS exposure promoted adipogenesis and suppressed lipolysis [15]. In this study, we focused on the effects of sucralose, one of the widely used NNS, on ROS accumulation and adipogenesis of human subcutaneous adipose tissue-derived mesenchymal stromal cells (hMSCs).

\section{Methods}

In vitro cell culture

ROS production detection in presence of normal glucose and high glucose and corresponding gene expression profile

Human mesenchymal stromal cells (hMSCs) were obtained from Lonza Inc.(Walkersville, MD, USA). They were cultured in Dulbecco's modified Eagle's medium (DMEM). hMSCs were exposed to high $(25 \mathrm{Mm})$ and normal (5.5 $\mathrm{Mm})$ glucose media in the presence of sucralose $(0 \mathrm{mM}$, $0.2 \mathrm{mM}, 0.45 \mathrm{mM}$, and $1 \mathrm{mM}$ ) for $72 \mathrm{~h}$ followed by gene expression analysis and Mitosox Red staining. The gene expression profile was directed towards adipogenesis (CEBPa, PPARG), antioxidants (SOD 1, SOD2, SOD3, Catalase, GPX1, GPX3), and glucose transporters (GLUT1 and GLUT4). We choose $72 \mathrm{~h}$ as the time point for all our experiments to observe discernable intracellular ROS accumulation with Mitosox staining.

\section{Detection of adipogenesis in presence of adipogenic media} hMSCs were exposed to adipogenic media (Lonza, Walkersville, MD, USA) in the presence of sucralose (0 $\mathrm{mM}, 0.2 \mathrm{mM}$, and $1 \mathrm{mM}$ ) for 3 cycles of induction and 3 cycles of maintenance ( 18 days) followed by gene expression analysis and Oil Red $\mathrm{O}$ staining.

\section{RNA extraction, CDNA synthesis, and gene expression in hMSCs and subcutaneous fat}

Quantitative reverse transcriptase polymerase chain reaction (qRT-PCR) was used for gene expression analysis. Total mRNA from hMSCs was isolated by RNeasy Mini Kit (Qiagen, Hilden, Germany). T100 Thermal Cycler (Bio-Rad, Hercules, CA) was used to convert mRNA to cDNA using the High Capacity cDNA Reverse Transcription Kit (Applied Biosystems, Foster City, CA). CFX96 Real-Time qPCR System (Bio-Rad) was used to analyze the genes of interest using TaqMan Universal Master Mix II (Applied Biosystems, Foster City, CA). Expression of individual genes was normalized to housekeeping genes (18S or GAPDH).

\section{Mitosox Red staining}

hMSCs were exposed to normal glucose $(5.5 \mathrm{mM})$ and high glucose $(25 \mathrm{mM})$ with $0 \mathrm{mM}, 0.2 \mathrm{mM}, 0.45 \mathrm{mM}$, and $1.0 \mathrm{mM}$ sucralose for $72 \mathrm{~h}$. For Mitosox Red staining, $5 \mu \mathrm{M}$ working solution was made from the stock solution $(5 \mathrm{Mm})$ by adjusting with $\mathrm{HBSS} / \mathrm{Ca} / \mathrm{Mg}$ buffer. Cells were incubated in $1 \mathrm{ml}$ of $5 \mu \mathrm{M}$ Mitosox Red for $20 \mathrm{~min}$ at $37^{\circ} \mathrm{C}$ followed by washing with Hanks' Balanced Salt Solution (HBSS/Ca/Mg) buffer and fixed with $4 \%$ paraformaldehyde. Intensity of fluorescence was estimated by ImageJ.

\section{Oil Red 0 staining}

To prepare the stock solution of Oil Red O (Sigma), $0.5 \%$ Oil Red O was dissolved in isopropanol. Three parts of this stock solution were mixed with 2 parts of phosphate-buffered saline (PBS) to make working Oil Red O solution. hMSCs were stained by Oil Red O working solution for $20 \mathrm{~min}$, followed by 3 washes with PBS.

\section{Cell viability test}

Cell viability was performed using trypan blue exclusion test, during the same setting as the differentiation experiment.

\section{Statistical analysis}

Results were analyzed by using unpaired $t$ test with $p$ values ${ }^{*}<0.05$ considered statistically significant.

\section{Results}

Mitosox Red staining of cells exposed to normal and high glucose with or without sucralose

The presence of reactive oxygen species (ROS) was examined by Mitosox Red staining in the presence of normal glucose: no statistically significant changes in ROS accumulation were observed in any of the sucralose-exposed conditions (0.2 mM, 0.45 mM, $1 \mathrm{mM}$ ) (Fig. 1a, b).

A trend of reduction (1.4-fold, $p=0.09$, between 0 and $1 \mathrm{mM}$ ) in MSC viability was observed with increasing doses of sucralose (Fig. 1c). A major reduction in cell viability was noted between 0 and $0.2 \mathrm{mM}$.

Significant upregulation of antioxidant gene such as extra-cellular glutathione peroxidase (GPX3) and gene associated with adipogenic differentiation such as CCAA T/enhancer-binding protein alpha $(\mathrm{CEPBa})$ genes was observed in response to sucralose exposure with the same set of cells mentioned above in Fig. 1a. Here, MScs were exposed to normal glucose media containing sucralose concentrations of 0.2 to $1 \mathrm{mM}$.

When human mesenchymal stromal cells (hMSCs) were exposed to $0 \mathrm{mM}$ and $1 \mathrm{mM}$ sucralose (Fig. 1d), the main upregulated genes again were GPX3 and CEBPA (2.6- and 5.2-fold, $p=0.03$ and 0.008 , respectively). The 


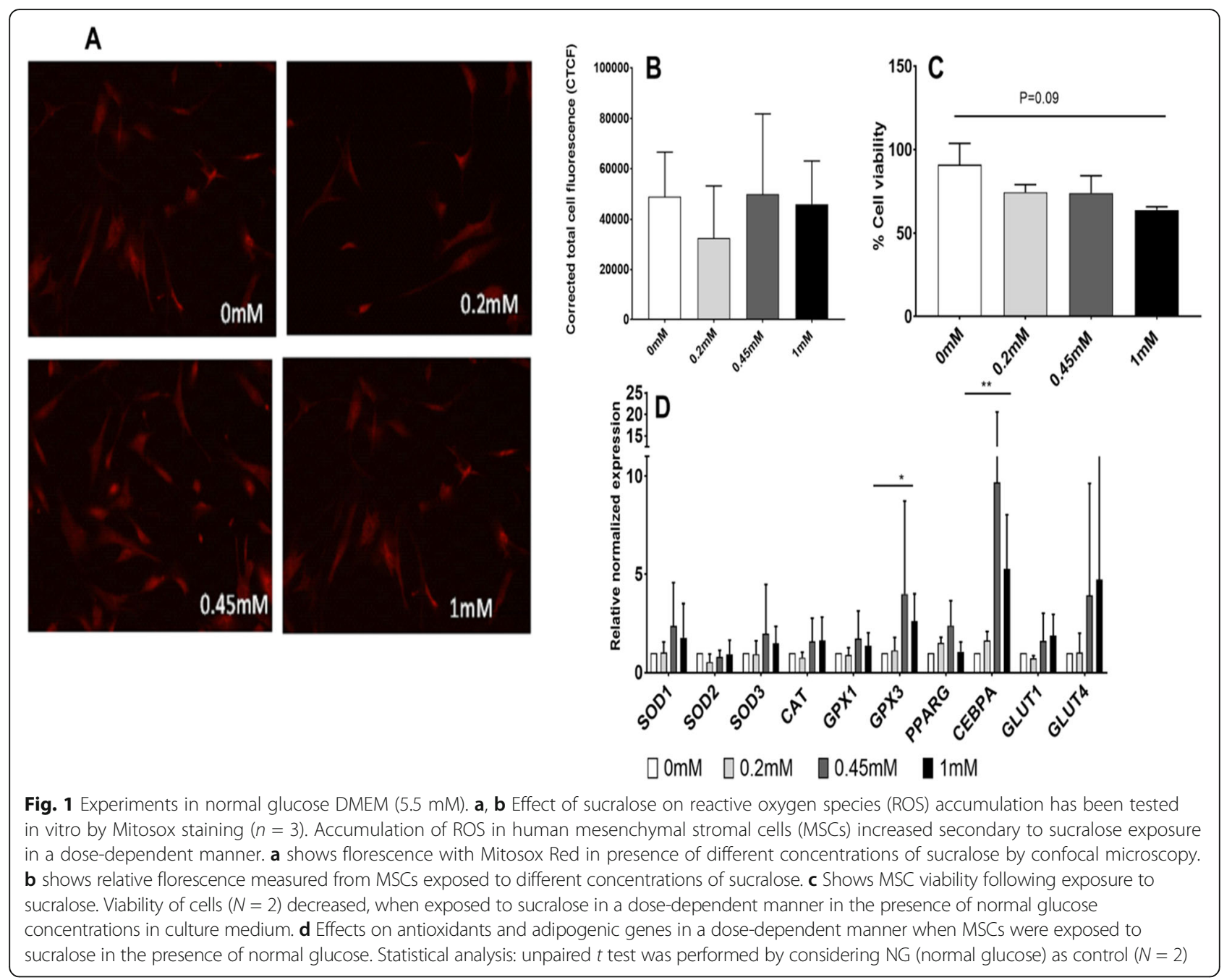

gene upregulation was not noted at $0.2 \mathrm{mM}$ but noted at $0.45 \mathrm{mM}$ and $1 \mathrm{mM}$ sucralose concentrations.

When the presence of reactive oxygen species (ROS) was examined in the presence of high glucose (DMEM $25 \mathrm{mM}$ glucose) using Mitosox Red staining, elevated ROS accumulation was observed (Fig. 2a, b). ROS accumulation increased (1.4-, 1.4-, and 1.7-folds, $p=0.009$, 0.001 , and 0.0001 , respectively) when cells were exposed to $1 \mathrm{mM}$ sucralose in comparison to control (absence of sucralose) (by ImageJ analysis,).

Of note, cell florescence secondary to ROS accumulation was higher (above 60,000 CTFC units) in all conditions in the presence of high glucose, compared to normal glucose.

Cell viability analyses (by trypan blue exclusion method) showed a decrease of 1.5 -fold and 1.4-fold respectively $(p=0.03$ and 0.03 , respectively) when cells were exposed to $1 \mathrm{mM}$ sucralose in comparison to $0 \mathrm{mM}$ sucralose and $0.2 \mathrm{mM}$ (Fig. 2c). There was a decrease in viability between 0.2 and $1 \mathrm{mM}$ indicating accumulating effect of cell toxicity in a dose-dependent fashion.
We also observed significant upregulation of antioxidant and adipogenic differentiation genes with same sets of cells mentioned previously in Fig. 2a when cells were exposed to high glucose (Fig. 2d). Genes including SOD3 (superoxide dismutase 3 , an extra-cellular antioxidant), GPX1 (glutathione peroxidase 1, an cytosolic antioxidant), and GPX3 (1.6-, 1.6-, and 1.7-fold, $p=0.01,0.03$, and 0.02, respectively) were also upregulated in this experimental set when comparing human mesenchymal stromal cells (hMSCs) exposed to $0 \mathrm{mM}$ and $1 \mathrm{mM}$ sucralose.

Adipogenic genes such as CEBPa and PPARG were upregulated in an increasing dose-dependent fashion of sucralose concentration, in the presence of high glucose (HG).

Viability of hMSC was decreased in the presence of high glucose in comparison to normal glucose (Figs. 1c and $2 \mathrm{c}$ ) in the same concentration of sucralose.

\section{Effects of sucralose on adipogenic differentiation}

hMSCs were exposed to adipogenic media (Lonza, Walkersville, MD, USA), to mimic an obesogenic 


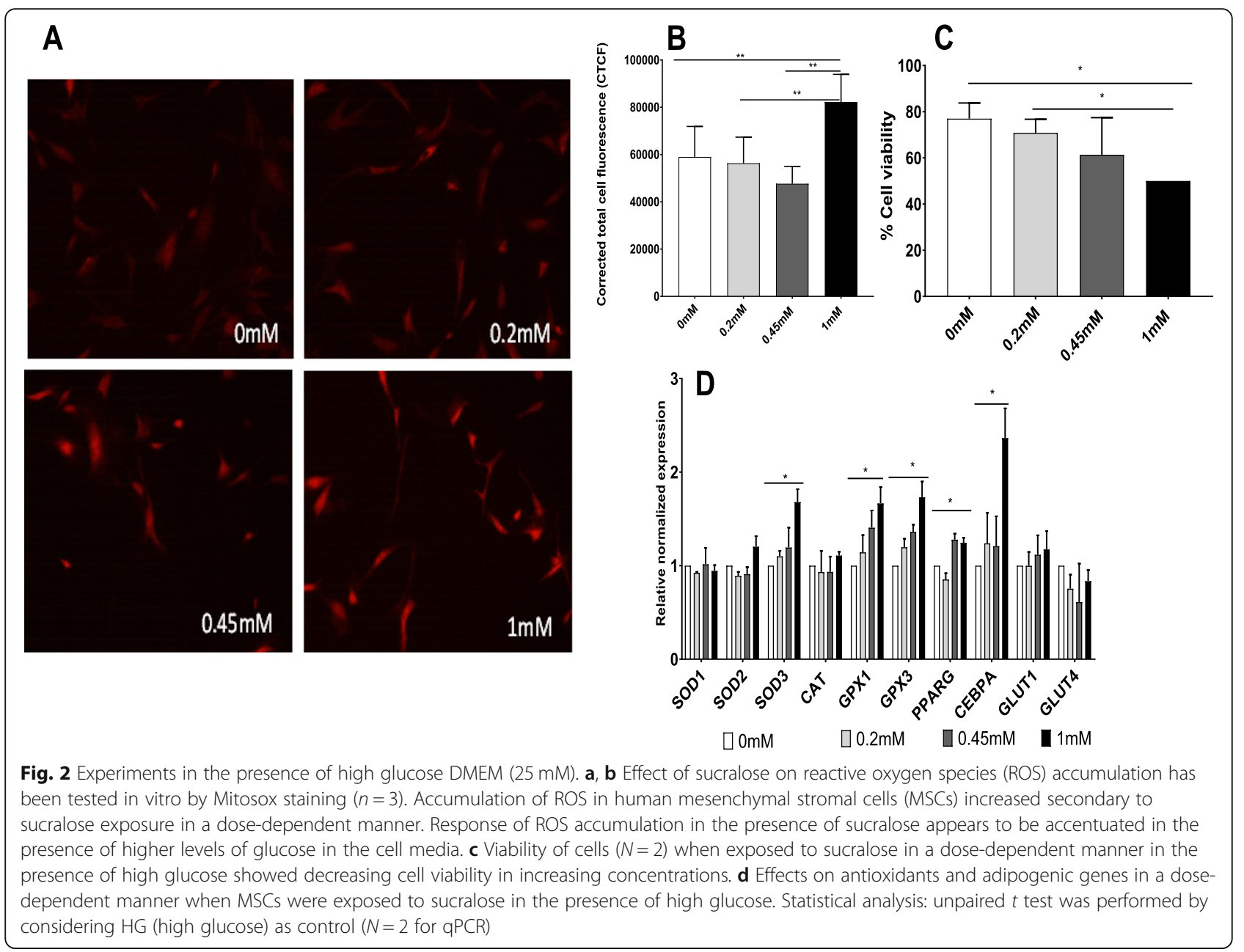

environment. Zero millimolar, $0.2 \mathrm{mM}$, and $1 \mathrm{mM}$ sucralose were added to the adipogenic media and cultured for 18 days (much longer period than $72 \mathrm{~h}$, following standard differentiation times for MSCs). Gene expression analysis demonstrated a relative upregulation of genes associated with increased intracellular fat, such as CEBPA, FABP4 (fatty acid binding protein or adipocyte protein 2 is a carrier protein for fatty acid and primarily expressed in adipocytes), and ADIPOQ (adiponectin, a protein hormone produced in mature adipocytes), 2.05fold, 3.45 -fold, and 3.5 -fold with $p$ values less than 0.05 , respectively (Fig. 3a).

We also stained hMSCs exposed to adipogenic media and sucralose with Oil Red $O$ to identify oil droplet (Fig. 3b), as an indication of the adipogenesis process.

\section{Discussion}

Our in vitro data showed increased adipogenesis and antioxidant expression with sucralose in a dose-dependent manner in a high glucose environment. There appears to be a compensatory upregulation of antioxidant genes, in response to increased intracellular ROS, noted on Mitosox
Red staining [16-18]. We detected quantifiable amount of Mitosox Red (Thermo-Fisher) staining at $72 \mathrm{~h}$, though minimal staining was evident as early as $24 \mathrm{~h}$. Notably, ROS accumulation is also reported in response to increased sugar intake and promotes the development of cardiovascular disease [19]. Our data confirms that there is increased ROS accumulation (by florescence strength) in the presence of high glucose compared to normal glucose [20].

It is important to distinguish cellular ROS or mitochondrial ROS presence difference. The main sources of cellular ROS are mitochondria and NADPH oxidases (NOXs). ROS produced in the mitochondria (mtROS) compared to NOX-generated ROS were initially considered to be unwanted by-products of oxidative metabolism though recent evidence indicates that mtROS have been incorporated into signaling pathways including those regulating immune responses, inflammation, autophagy, and cell differentiation. Mitosox Red stain from Thermo-Fisher specifically targets the mitochondria and is rapidly oxidized by superoxide which is primarily produced in the mitochondria. In our figures, we see 

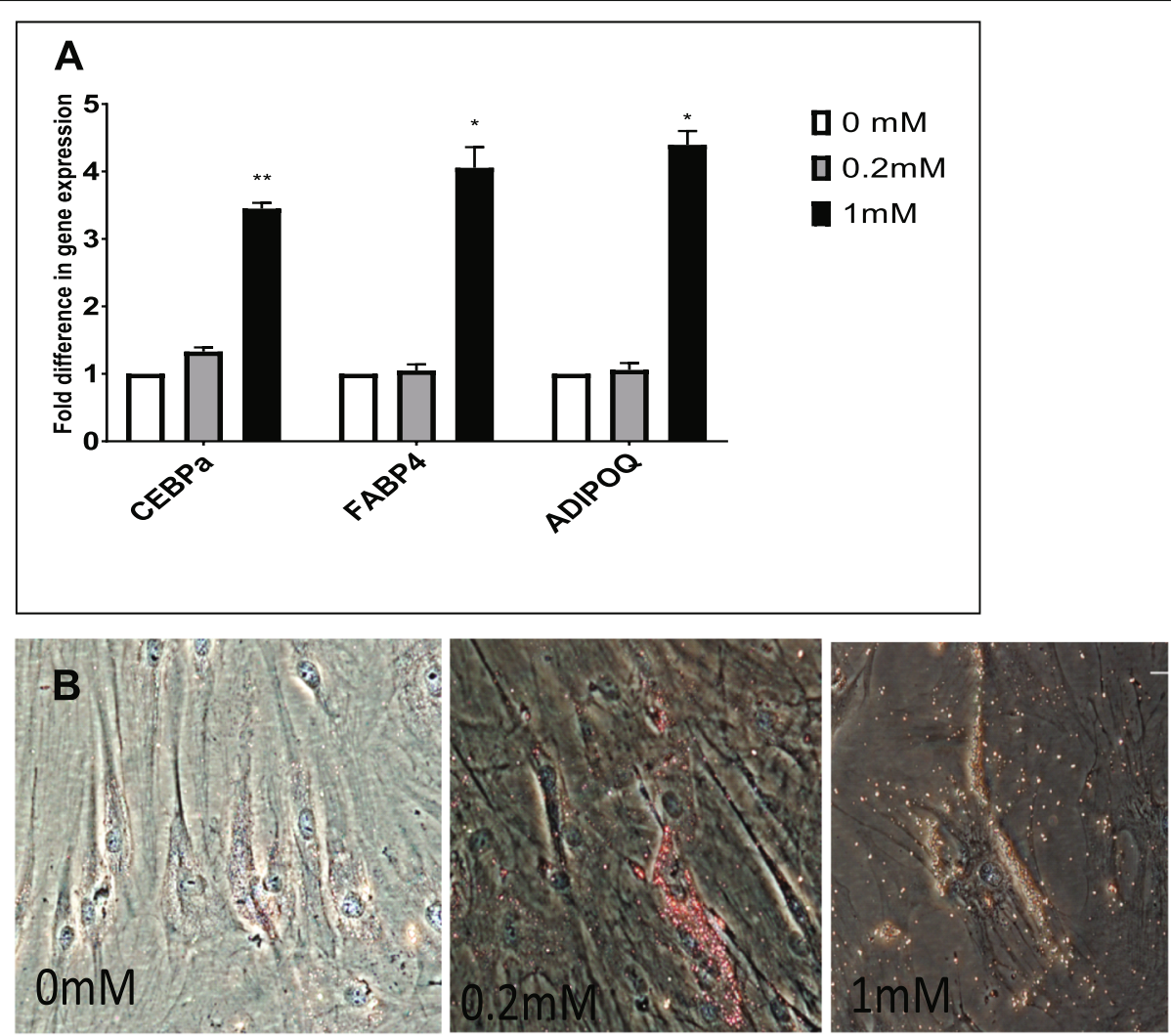

Fig. 3 a Effects of sucralose on human mesenchymal stromal cells (MSCS) at 18 days observed by gene expression analysis. Genes associated with increased intracellular fat, such as CEBPA, FABP4, and adiponectin, upregulated in a dose-dependent manner. Clearly high expression levels were noted at $1.0 \mathrm{mM}$, but there was clear upregulation of adipogenic genes in the presence of $0.2 \mathrm{mM}$ (a physiological dose). Statistical analysis was performed by considering $0 \mathrm{mM}$ as control $(n=2)$. The mRNA expressions were compared to relative values to adipogenic media without sucralose $(0 \mathrm{mM})$. $\mathbf{b}$ Effect of sucralose on adipogenic differentiation. MSCs were exposed to adipogenic media for 18 days followed by Oil Red $\mathrm{O}$ staining. Increasing number of oil droplet with higher concentrations of sucralose indicates the increased presence of intracellular fat. Cells at 1.0 $\mathrm{mM}$ sucralose are sparse, but viable cells were packed with lipid droplets

Mitosox Red staining in the cytosol; however, we believe that the source of ROS is the mitochondria.

While our in vitro findings require further corroborative studies in vivo, our results suggest that consuming sucralose may promote metabolic dysfunction by promoting ROS accumulation intracellularly which initially starts in the mitochondria, and subsequently, the ROS and Mitosox staining is evident in the cytosol. We have previously shown that ROS accumulation (in conditions such as hyperglycemia) can be associated with increased adipogenic differentiation of human MSCs. We noted increased ROS accumulation in the presence of high concentrations of sucralose in normal and high glucose media with concomitant increase in adipogenic genes such as CEBP-alpha. The increased intracellular ROS accumulation appears to be more pronounced in the presence of high glucose compared to normal glucose. Therefore, these findings may be particularly relevant to a hyperglycemic milieu in a clinical setting such as diabetes compared to a state without diabetes. More importantly, the ROS accumulation features were noted quite definitively, within $72 \mathrm{~h}$ of exposure to sucralose either in normal or in high glucose, indicating the relative quick onset of ROS production and accumulation following sucralose exposure.

Our previous work on human adipogenic MSCs have shown mitochondrial complex 1 dysfunction in the presence of high glucose secondary to superoxide activity. We demonstrated that upregulation of a mitrochondrial antioxidant such as superoxide dismutase 2 (SOD2) reduced oxidative stress and prevents adipogenesis. Similarly, increased intracellular ROS in the presence of sucralose is expected to impair mitochondrial function with subsequent less energy production and accumulation of substrate such as glucose accumulation as lipid droplets (as seen in this case) leading to increased adipogenesis [20, 21].

The increased intracellular ROS accumulation, postsucralose exposure, most likely triggers reactive antioxidant gene mRNA upregulation, which could be an acute response reaction to increased intracellular ROS accumulation.

It may be worthwhile to do follow-up studies to investigate the duration of this response in relation to ROS 
production secondary to sucralose exposure. However, the degree of ROS production and duration of action would depend on plasma sucralose levels.

As sucralose may manipulate glucose transporter expression, we tested two glucose transporters' (GLUT1 and GLUT4) mRNA expression in the presence of normal and high glucose with varying concentrations of sucralose; we did not find any obvious differences in expression across the concentrations (Figs. 1d and 2d) indicating that GLUTs may not play a role in sucralose effects on human MSCs.

Lastly, our results indicate increased mature fat droplet accumulation in vitro, as seen under light microscope in the presence of higher concentration of sucralose, at both 0.2 and $1 \mathrm{mM}$, at day 18 , of adipogenic media exposure. As mentioned before, $0.2 \mathrm{mM}$ sucralose in culture media will be closer to physiological level that can be achieved on NNS consumption [7, 13].

It may be speculated that early production of ROS, by $72 \mathrm{~h}$, leads to increased mature fat-like cells (with increased fat droplets) by day 18 , associated with mature fat genes such as FABP4 and ADIPOQ along with fat transcription factor gene upregulation such as CEBPalpha.

\section{Conclusion}

The experiments that we have described here are a prelude to human in vivo mechanistic studies. There are several human studies that epidemiologically indicate a possible connection between artificial sweetener consumption and metabolic dysregulation. Our experiments are novel and for the first time establish a possible cellbased mechanism of how sweeteners may influence differentiation of fat-based stem cells in humans and promote adipogenesis. Based on our literature search, this is the first study to use human adipose tissuederived hMSCs to discern the effect of sucralose on fat precursors in humans. These cells are multipotent cells and as per embryology can differentiate into myocytes, chrondrocytes, osteocytes, and adipocytes depending on the cellular milieu [20]. Certain conditions augment their differentiation towards adipogenesis, and increased intracellular ROS accumulation is one of those factors $[20,21]$. Artificial sweetener such as sucralose promotes intracellular ROS accumulation in a dose-dependent fashion and more so in a hyperglycemic milieu compared to normoglycemic milieu at all concentrations of sucralose. The interesting part is that the ROS production occurs almost immediately and discernable by $72 \mathrm{~h}$ in spite of no obvious cell toxicity.

Our results highlight the need for further in vivo studies, measuring production and accumulation of reactive oxygen species, in a dose-dependent fashion as well as increased fat accumulation, leading to increased insulin resistance and CVD. In fact, our in vivo study [22] indicates that sucralose promotes acute inflammatory response and our in vitro results suggest that rapid and immediate ROS accumulation may be the mechanism. Our results explain adverse associations between NNS consumption and cardiometabolic health reported in epidemiological studies at a cellular level.

\section{Acknowledgements \\ We would like to acknowledge contributions of Dr. Kristina Rother, Senior Investigator, NICHD, in helping with the concept of this project.}

\section{Authors' contributions}

NK conducted the experiments and compiled the figures and manuscript. CCD conducted the experiments and revised the manuscript. JP conducted the experiments and helped in compiling the results. MA conducted the experiments and helped in compiling the results. NA conducted the experiments. MF conducted the experiments and helped in compiling the results. ACS helped in the concept and revised the manuscript. SS developed the concept, supervised the experiments, and drafted the manuscript. All authors have agreed to the submission.

\section{Funding}

The study has been conducted using the George Washington University Internal Funds given to S. Sen.

Availability of data and materials

All materials are freely available on written request to Dr. Sen.

Ethics approval and consent to participate

Involves only human cells, not applicable

\section{Competing interests}

The authors declare that they have no conflict of interests. No individual or personal data has been included.

\section{Author details}

${ }^{1}$ The George Washington University, 2300 Eye ST. NW, Washington DC 20037, USA. ²Department of Exercise and Nutrition Sciences, Milken Institute School of Public Health, The George Washington University, Washington DC, USA.

Received: 9 January 2020 Revised: 27 May 2020

Accepted: 1 June 2020 Published online: 26 June 2020

References

1. Rippe MJ, Angelopoulos JT. Relationship between added sugars consumption and chronic disease risk factors: current understanding. Nutrients. 2016:8(11):697.

2. Vos MB, Kaar JL, Welsh JA, Van Horn LV, Feig DI, Anderson CAM, Patel MJ, Munos JC, Krebs NF, Xanthakos SA, Johnson RK. Added sugars and cardiovascular disease risk in children: a scientific statement from the American Heart Association. Circulation. 2016;135:19.

3. DiNicolantonio J, OKeefe JH. Added sugars drive coronary heart disease via insulin resistance and hyperinsulinaemia: a new paradigm. Open Heart. 2017:4(2):000729.

4. Welsh JA, Sharma A, Abramson JL, Vaccarino V, Gillespie C, Vos MB. Caloric sweetener consumption and dyslipidemia among US adults. JAMA. 2010; 303(15):1490-7.

5. Added Sugars. American Heart Association. 2018. http://www.heart.org/ HEARTORG/HealthyLiving/HealthyEating/Nutrition/Added-Sugars_UCM_305 858_Article.jsp\#.Wud7KS7waUk.

6. Sylvetsky AC, Welsh JA, Brown RJ, Vos MB. Low-calorie sweetener consumption is increasing in the United States. Am J Clin Nutr. 2012;96(3):640-6.

7. Sylvetsky AC, Jin Y, Clark EJ, Welsh JA, Rother KI, Talegawkar SA. Consumption of Low-Calorie Sweeteners among Children and Adults in the United States. J Acad Nutr Diet. 2017;117(3):441-448.e2. https://doi.org/10. 1016/j.jand.2016.11.004. Epub 2017 Jan 10. 
8. Ruanpeng D, Thongprayoon C, Cheungpasitporn W, Harindhanavudhi T. Sugar and artificially sweetened beverages linked to obesity: a systematic review and meta-analysis. QJM. 2017;110(8):513-20.

9. Azad MB, Abou-Setta AM, Chauhan BF, Rabbani R, et al. Nonnutritive sweeteners and cardiometabolic health: a systematic review and metaanalysis of randomized controlled trials and prospective cohort studies. CMAJ. 2017;189(28):929-39.

10. Sharma A, Amarnath S, Thulasimani M, Ramaswamy S. Artificial sweeteners as a sugar substitute: are they really safe? Indian J Pharmacol. 2016;48(3):237-40.

11. Hall LN, Sanchez LR, Hubbard J, Lee H. Aspartame intake relates to coronary plaque burden and inflammatory indices in humanimmunodeficiency virus. Open Forum Infect Dis. 2017;4(2):ofx083.

12. Smeets PA, de Graaf C, Stafleu A. Functional magnetic resonance imaging of human hypothalamic responses to sweet taste and calories. Am J Clin Nutr. 2005;82(5):1011-6.

13. Jotham S, Hagit S, Eran E. Role of the microbiome in the normal and aberrant glycemic response. Clin Nutr Exp. 2016;6:59-73.

14. Palmnäs MS, Cowan TE, Bomhof MR, Su J, Reimer RA, Vogel HJ, Hittel DS, Shearer J. Low-dose aspartame consumption differentially affects gut microbiota-host metabolic interactions in the dietinduced obese rat. PLoS One. 2014;9(10):e109841. https://doi.org/10.1371/journal.pone.0109841.

15. Simon BR, Parlee SD, Learman BS, et al. Artificial sweeteners stimulate adipogenesis and suppress lipolysis independently of sweet taste receptors. J Biol Chem. 2013;288(45):32475-89.

16. Ho YS, Magnenat JL, Gargano M, Cao J. The nature of antioxidant defense mechanisms: a lesson from transgenic studies. Environ Health Perspect. 1998;106(Suppl 5):1219-28.

17. Poljsak B, Šuput D, Milisav I. Achieving the balance between ROS and antioxidants: when to use the synthetic antioxidants oxidative medicine and cellular longevity. Oxidative Med Cell Longev. 2013;956792:11.

18. Birben E, Murat U, Sackesen SC. Oxidative stress and antioxidant defense. World Allergy Organ J. 2012;5(1):9-19.

19. Prasad K, Dhar I. Oxidative stress as a mechanism of added sugar-induced cardiovascular disease. Int J Angiol. 2014;23(4):217-26.

20. Sen S, Dominguez C, Rouphael C, Chou C, Kim C, Yadava N. Genetic modification of human mesenchymal stem cells helps to reduce adiposity and improve glucose tolerance in an obese diabetic mouse model. Stem Cell Res Ther. 2015;6:242.

21. Domingues CC, Kundu N, Kropotova Y, Ahmadi N, Sen S. Antioxidant upregulated mesenchymal stem cells reduce inflammation and improve fatty liver disease in diet-induced obesity. Stem Cell Res Therapy. 2019;10(1):280.

22. Sylvetsky AC, Sen S, Merkel P, et al. Consumption of Diet Soda Sweetened with Sucralose and Acesulfame-Potassium Alters Inflammatory Transcriptome Pathways in Females with Overweight and Obesity. Mol Nutr Food Res. 2020;64(11):e1901166. https://doi.org/10.1002/mnfr.201901166.

\section{Publisher's Note}

Springer Nature remains neutral with regard to jurisdictional claims in published maps and institutional affiliations.

\section{Ready to submit your research? Choose BMC and benefit from:}

- fast, convenient online submission

- thorough peer review by experienced researchers in your field

- rapid publication on acceptance

- support for research data, including large and complex data types

- gold Open Access which fosters wider collaboration and increased citations

- maximum visibility for your research: over $100 \mathrm{M}$ website views per year

At $\mathrm{BMC}$, research is always in progress.

Learn more biomedcentral.com/submissions 